\title{
A new role of unruly product design based on "Transformed Objects" design approach
}

\author{
Athanasios Manavis ${ }^{1, *}$, Nikoleta Kapakiari ${ }^{1}$ and Gheorghe Oancea ${ }^{2}$ \\ ${ }^{1}$ Western Macedonia University of Applied Science, Department of Mechanical Engineering and \\ Industrial Design, Kila Kozani GR50100 Greece \\ 2 Transilvania University, Department of Manufacturing Engineering, Braşov, RO500036, Romania
}

\begin{abstract}
Nowadays, the movement of Post-Modernism, which appeared in 20th century, influences the art and the design of products. It is considered that the investigation and the undermining, which construct the modern society, compel a traditional prioritization based on cultural values. Furthermore, today the main effect is the image as the users opt to purchase their products by the appearance that is more substantial than the usage. For that reason, the alteration of daily products is the cause of this paper so that the consumers feel confused by them. Namely the basic image of a product may be the same as or similar to an original object, but it may alter the use of it. The viewer should interpret the image differently such as his experience and his belief. In addition, the change of visual messages can be achieved by the complexity of geometry, the combination of objects and the modification of materials. This is defined by the movement of Unruly design that aims for offering a new aesthetic of products. Finally, the goal of this paper is to present a number of illustrative case studies, which ensure an appropriate interface relationship between the art and product design.
\end{abstract}

\section{Introduction}

The optical aesthetics is a factor which influences the users so as to purchase a new product. Therefore, the main reason, which this paper investigates, is the image of the products (Figure 1) [1]. Moreover, users try to buy new objects which help them in a daily basis and these fulfil their needs. However, the principal motivation is the appearance and the aesthetics in order to opt for such a product. Nowadays, the image of the product becomes more important than the product itself [2]. This reveals a new way of thinking, in which people observe and want to follow their subjective aesthetics of products [3].

The contemporary society investigates every aspect so that the things will be designed in a way of perfection. A modern theory that describes the relationship between the image of the product and the product itself is the unruly design [4]. Furthermore, the ergonomics of products is a goal which every designer should succeed so that the usage of objects will be obvious.

\footnotetext{
* Corresponding author: manavis.athanasios@gmail.com
} 


\section{Unruly design}

The movement of unruly design appeared at the end of the 20th century and the focus of product design has shifted from primarily offering functionality towards experience and emotion driven product characteristics. According to the theory of product phases, the design of mature product types will end in a phase characterized by extended segmentation, individualization or awareness [4]. In the unruly design, there are some subdivisions such as combining different interest domains, use inspiration from popular culture, incorporate form-complexity, make use of ready-mades and make use of uncommon material [3].

However, these categories are created so as to separate the unruly design in a particular section. In the unruly design approach, the affective, emotional, and abstract product values become important.

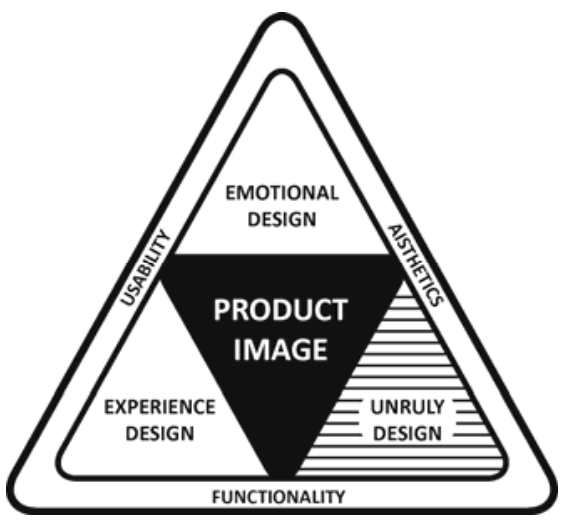

Fig. 1. The role of unruly design.

\section{Ergonomics}

The optical aesthetics is a factor which influences the users so as to purchase a new product. Product design has been defined as the development of manufactured products that serve the physical needs and satisfy the psycho-logical desires of people [5]. Ergonomics is a combination of human engineering aspects with human factors. Furthermore, ergonomics becomes even more relevant when it is necessary for a user to fulfil operation requirements in more complex systems [1]. The specialists of ergonomics require considerable design project experience to unify the constellations of human factors principles, facts and techniques into a powerful and practical item [6]. Designing consumer products requires a mixture of art and engineering, which can work harmoniously without dilution of each. In fact, the more attention that is paid to applying engineering and art towards the ends of users' safety and satisfaction, the more likely it is that the product will have a shaping influence on future design examples. Thus, the successful integration of ergonomics and industrial design will produce aesthetically pleasing and functionally superior products

\section{Transformed objects}

First of all, this paper presents a modern optical aesthetics and studies some movements of the contemporary art, which try to reduce the conceptual image of the products. The transformed objects approach is influenced by the surrealism, the Dada art movement and the unruly design [7]. The aim of this study is to transform some daily products so as to destroy their image. In this way, the user should rethink the usage of the particular objects 
so that we will notice if they want to include these products in their lives. Through these objects, some consumers will be disgusted, get irritated, be glad and get excited. There will be so many mixed feelings, which will create the success of these products. In addition, the transformed objects design approach gives a new impression in which people will not consider using these things in this way. In comparison with the art the design of products has got some theoretical meanings, which have to be included in the objects. The main core of the theory is the deconstruction of daily products so as to design objects, which are the same, but they have different use (Figure 2) [8]. This is the main idea to start an innovative design approach.

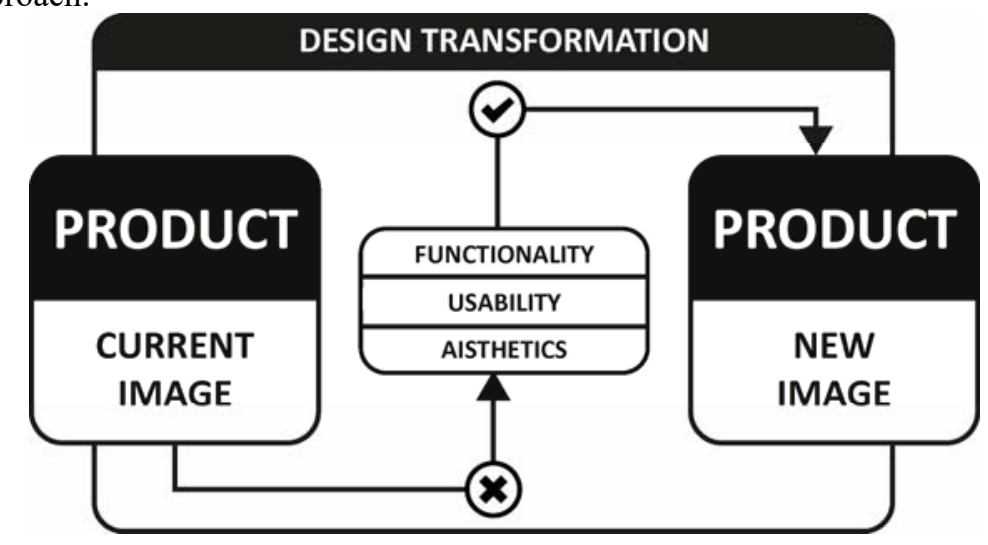

Fig. 2. The design transformation process.

\subsection{Lighter - Bottle of water}

The lighter is an object that many people use every day, such as their mobile phone or their keys. Smokers use their lighters in order to take pleasure in their favourite habit. But there are some people who do not need them in their daily lives.

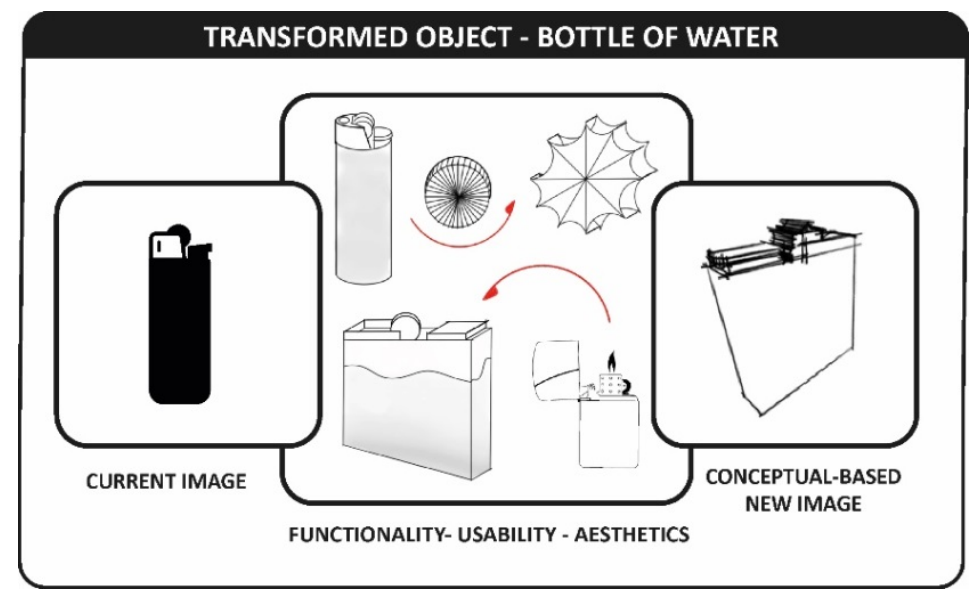

Fig. 3. A lighter is transformed to a bottle of water.

This modern product was designed to presents a new approach, which will be essential for people's lives. The first thought was the lighter to become a bottle of wine, in fact to compare the wine with the fire. Nevertheless, it was decided to create an object which will have dissimilar notions (Figure 3). Finally, this design example presents a bottle of water which had the same image with the lighter. Furthermore, they decided to change the 
materials of the lighter. The metal items of the lighter will be transformed to wooden, and the plastic ones will be made of glass. This way, the consumer will try to think of the use and he will wonder how a lighter can contain water which he can drink (Figure 4).

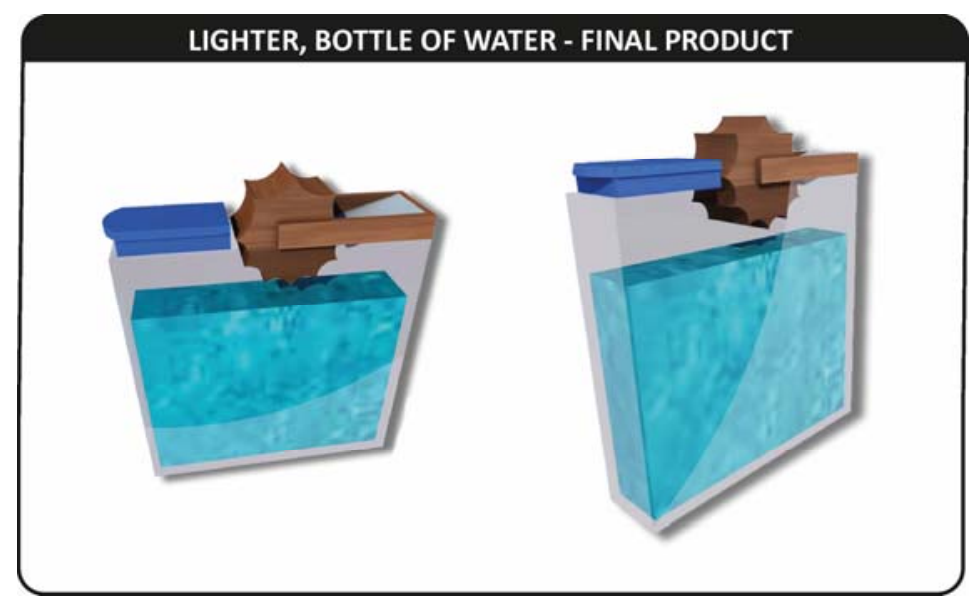

Fig. 4. The final image of the product.

\subsection{Trash bin - Musical instrument}

The bin is a necessary daily tool because we dispose our garbage. Deconstructing the concept of the bin, it is observed that during the usage of this product the consumers find pleasure in pushing the pedal (Figure 5). In this way, the bin makes a sound when the cap closes and the first thought was that this feature can be developed in a new product idea. Therefore, the final idea was to be created a musical instrument, which had the same image with the bin. This product can be used by children who will enjoy it in their spare time (Figure 6). The mechanism will be placed in the centre of the bin so that the cap will make the sound because it is metal. The shell of this bin will be soft paper so as to diffuse the sound.

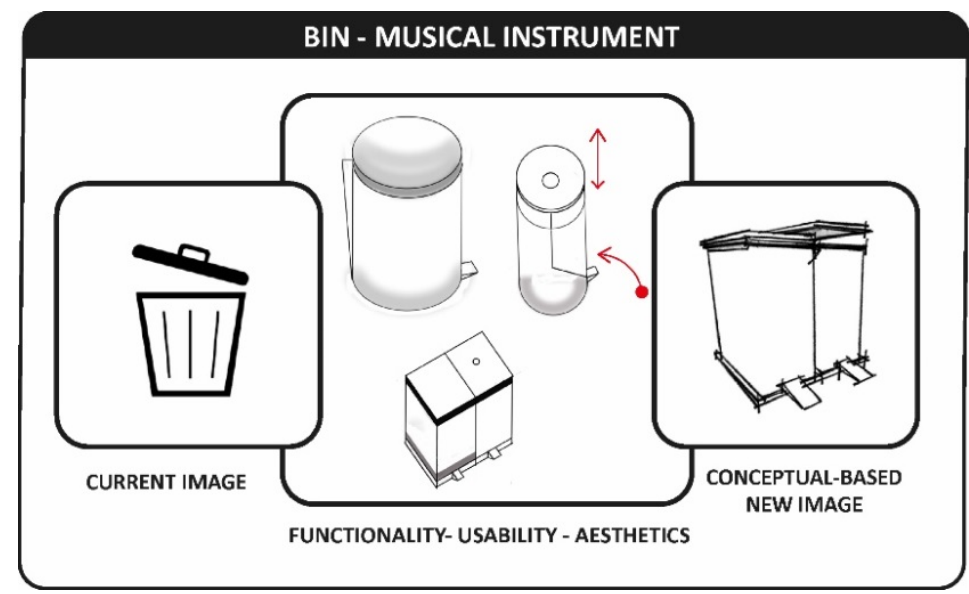

Fig. 5. A trash bin transformed to a musical instrument. 


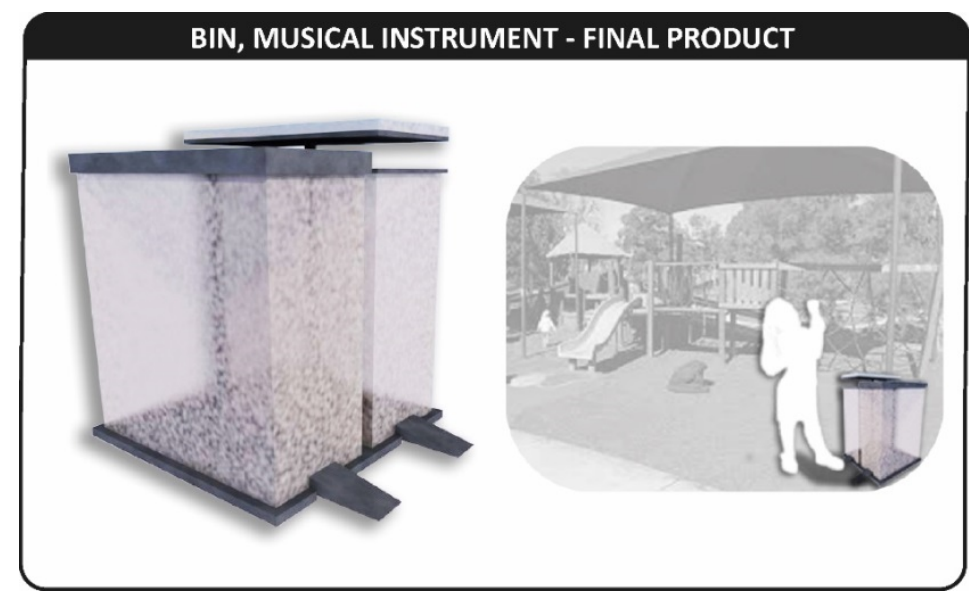

Fig. 6. The final image of the product.

\section{Conclusions}

The optical aesthetics depends on each person as he can interpret the image of the product differently. This paper presents a contemporary notion of the objects that are rarely used. A unusual methodology was presented based on the creation of transformed objects. Transformed objects are a combination of three factors: unruly design, Dadaism and ergonomics. Through these design case studies, the designer desires to deconstruct the objects so that people could analyse each of them before they use them. In doing so, the consumers will try to understand the product and the designer. Finally, this framework offers unique design and marketing advantages to companies. In fact, it is noticeable that nowadays many people tend to buy a product based on its appearance.

\section{References}

1. P. Kyratsis, N. Efkolidis, Ath. Manavis, A. Tsagaris, AMM 809-810(2), 1311, (2015)

2. P. Kyratsis, Ath. Manavis, C. Garcia-Hernandez, N. Efkolidis, AMM 657, 1021, (2014)

3. P. Hekkert, H. Leder, Product Aesthetics: Product Experience (Elsevier Science, 2008)

4. W. Eggink, A. Reinders, $5^{\text {th }}$ International Congress of International Association of Societies of Design Research, Tokyo (2013)

5. L. Rungtai, J.G. Kreifeldtb, Int J Ind Ergonom 27, 259 (1999)

6. L. Rungtai, J.G. Kreifeldt, Proceedings of the Human Factors Society (1992)

7. A. Manavis, G. Pliatsios, E. Dimou, A. Korlos, P. Kyratsis, $21^{\text {th }}$ Innovative Manufacturing Engineering and Energy Conference, Romania (2017)

8. Gh. Oancea, L.A. Chicoş, C. Lancea, $3^{\text {rd }}$ WSEAS International Conference on Engineering Mechanics, Structures, Engineering Geology, Corfu Island, Greece (2010) 